\title{
LENGUAJE Y PERSUASIÓN EN ARMORUM IUDICIUM. METAMORFOSIS DE OVIDIO 13.1-398
}

\author{
Language and persuasion in Armorum iudicium. Ovid's Metamorphoses 13.1-398
}

\author{
Marcela Inés Coll* \\ Universidad Nacional de San Juan \\ marcelaicoll@hotmail.com
}

\author{
María Celina Perriot** \\ Universidad Nacional de San Juan \\ celperriot@gmail.com
}

Palabras clave

retórica;

juicio de las armas;

pragmadialéctica;

eloquentia;

virtus

Keywords

rethoric;

contest for the arms;

pragma-dialectics;

eloquentia;

virtus

\section{Resumen}

En este artículo nos proponemos el abordaje del episodio Armorum iudicium (Ov. Met.13.1-398) en tanto discurso argumentativo, desde una perspectiva pragmadialéctica. Entendemos que el propósito central de este tipo de discurso es la persuasión, es decir, la necesidad de afectar al destinatario de diversas maneras (hacer-hacer, hacer-creer, etc.). Analizaremos las estrategias discursivas utilizadas tanto por Áyax como por Ulises para lograr su objetivo: la consecución de las armas, frente a sus compañeros de batalla quienes se erigirán como árbitros. En este contexto, el lenguaje asume un rol fundamental como instrumento de poder, ya que comporta una orientación hacia cierto tipo de intervención en un destinatario. El poder del discurso, en este sentido, radicaría en ese trabajo por el cual el lenguaje asume el papel de constructor de visiones de mundo y permite convencer a un interlocutor para que piense o actúe de una manera determinada.

\begin{abstract}
The aim of this article is to approach the episode Armorum iudicium (Met. XIII, 1-385) as an example of argumentative speech. It is known that the main purpose of argumentation is persuasion, that is, the need of affecting the reader in different ways (make someone do something; make someone believe; etc.). We will analyze the strategies used by Ajax and by Ulysses to achieve their objective: getting the weapons in front of their battle mates, who will become judges. In this context, language takes the fundamental role of a power instrument, due to the fact that it has an orientation to certain kind of intervention on the recipient. The power of speech, in this sense, would rely on the function by means of which language takes the role of builder of world visions that allows convincing the interlocutor to think or react in a particular way.
\end{abstract}




\title{
Lenguaje y persuasión en Armorum iudicium. Metamorfosis de Ovidio 13.1-398
}

\author{
Denique (quid verbis opus est?) spectemur agendo
}

Ov. Met. 13.120

En este artículo nos proponemos el abordaje del episodio Armorum iudicium (Ov. Met.13.1398), con especial atención a los parlamentos de Áyax (5-122) y Ulises (128-381), en tanto discurso argumentativo, desde una perspectiva pragmadialéctica y dialógica bajtiniana. ${ }^{1}$ En este pasaje, los dos contrincantes, Áyax y Ulises, pretenden convencer a sus compañeros, reunidos en asamblea, para tomar la decisión acertada de entregar las armas de Aquiles al merecedor de las mismas. ${ }^{2}$

En el pasaje analizado se plantea una disputa en torno a la virtus en términos de acción o de palabras, encarnada respectivamente en Áyax y Ulises. Esta discrepancia debe ser solucionada a través de argumentos que refrenden alguna de las dos posturas, aspecto que nos lleva a reflexionar acerca de la dimensión pragmática o performativa del lenguaje.

Entendemos que el propósito central del discurso argumentativo es la persuasión, esto es, la necesidad de afectar al destinatario de diversas maneras (hacer-hacer, hacer-creer, etc.); entonces, analizaremos las estrategias discursivas utilizadas tanto por Áyax como por Ulises para lograr su objetivo: la consecución de las deseadas armas, frente a sus compañeros de batalla quienes se erigirán como árbitros. Ulises, encarnación misma de la elocuencia y astucia, rozando en ocasiones la inescrupulosidad, finalmente logra persuadir a la asamblea de ser el legítimo heredero de tan digno premio, a pesar de los sólidos argumentos de Áyax para mostrar/decir su protagonismo durante la guerra.

En este contexto, el lenguaje asume un rol fundamental como instrumento de poder, ya que comporta una orientación hacia cierto tipo de intervención en un destinatario. El poder del discurso, en este sentido, radicaría en ese trabajo por el cual el lenguaje asume el papel de "constructor de visiones de mundo que permite influir en el pensamiento del otro y eventualmente modificarlo" (Barei y Rinaldi, 1996, p. 8).

Desde la perspectiva bajtiniana, todo discurso puede ser analizado en su dimensión argumentativa, en tanto supone una interacción dialógica; es siempre la respuesta a un enunciado de un otro que lo precede. En efecto, acordamos con Bajtín en que el lenguaje puede ser entendido como una arena de luchas sociales y políticas: una "lucha” (dirá él) ideológica (2011).

1. La mención más antigua conservada sobre esta disputa mítica se encuentra en Odisea 11.543-546.

2. Según Ruiz de Elvira (1975, p. 429) "la elaboración retórica que sirvió de modelo a Ovidio (a la que este superó ampliamente) es la de Antístenes, en sus dos discursos conservados con los títulos de Ayax y Ulises”. 


\section{Algunas consideraciones teóricas}

Como bien sabemos, los estudios acerca de la dimensión argumentativa del discurso tienen larga data. Ha sido objeto de análisis desde la Retórica de Aristóteles pasando por diferentes fases.

En esta instancia, asumimos una perspectiva pragmadialéctica, disciplina que recupera elementos de análisis de la retórica clásica y los enriquece con nuevos aportes de la pragmática. La combinación de pragmática y dialéctica lleva a concebir todo intercambio argumentativo como una constelación de actos de habla interdependientes. Ya en el siglo XXI la pragmadialéctica ha incorporado a ese entramado básico el concepto de maniobra estratégica para dar cuenta de los aspectos retóricos de la argumentación, que tienen que ver con su efectividad suasoria (Carretero, 2015, p. 3).

En este marco, entendemos la argumentación como

un medio para resolver una diferencia de opinión. (...) como una actividad verbal, social y racional que apunta a convencer a un crítico razonable de la aceptabilidad de un punto de vista adelantando una constelación de una o más proposiciones para justificar ese punto de vista. (Van Eemeren et al., 2006, p. 17)

O sea, como un acto de habla que pretende persuadir a un auditorio determinado.

Aristóteles define la retórica como "la facultad de considerar en cada caso lo que puede ser convincente" (Rhet.1355b). Esto se lleva a cabo mediante argumentos que, según sus propios términos: "unos no pertenecen a la disciplina, otros sî". Para referirse a aquellos que él mismo denomina "argumentos procurados por el discurso" (es decir, no previos ni externos a él), el filósofo habla de tres “especies": los que residen en el comportamiento (ethos) del orador; los que ponen el acento en las disposiciones del oyente y, por último, los que se asientan en las características del propio discurso (Rhet.1356a).

Entonces, desde una perspectiva pragmadialéctica, consideraremos categorías que nos permitan abordar esta disputa verbal, tales como el desacuerdo inicial generado por diferentes puntos de vista o de opinión, los tipos de argumentos utilizados, los recursos, la validez en los diferentes momentos de la argumentación.

En este punto debemos tener presente además que estamos frente a un texto literario, género discursivo que, si bien tiene su matriz en un contexto histórico determinado, como es en este caso el judicial romano, lo refracta. ${ }^{3}$ Este discurso argumentativo está escrito en hexámetros; la oratoria romana empleaba la prosa, de modo que esta transposición de prosa a verso implica ciertas adaptaciones que determinarán, de alguna manera, la mayor elaboración/complejidad del tipo de recursos utilizados, por ejemplo, el ritmo métrico en relación con la gestualidad corporal. ${ }^{4}$

3. La metáfora de la refracción o del "prisma" apunta a establecer la complejidad de las mediaciones del objeto literario en relación con la "atmósfera" social porque "Una realidad no refractada ideológicamente, cruda, por decirlo así, no puede formar parte de un contenido literario" (Arán, 2006, p. 60).

4. Cfr. Tola (2010, p. 299-318) quien sostiene que "el poder de la palabra de Ulises radica en la conjunción de distintas estrategias que abarcan desde la gestualidad hasta la construcción fónico-métrica de su discurso". 


\section{La disputa}

Si bien el iudicium responde a los modelos del genus iudiciale romano, con algunos rasgos del genus deliberatioum (cfr. Amossy, 1999, p. 6), advertimos que más que un juicio parece un arbitraje, si lo pensamos en términos de legalidad. No se apunta a resolver una diferencia de opinión sino a convencer a un auditorium que tiene el poder de decidir, de dar el bien deseado, y que aún no estaría de acuerdo con el punto de vista de ninguno de los antagonistas. En un juicio, el juez atiende a la ley, en cambio en un arbitraje, el árbitro atiende a lo razonable. La confrontación analizada no pretende llegar a ningún tipo de acuerdo entre los adversarios, sino que se trata de lograr la adhesión del auditorio a uno de ellos, como sugiere Aristóteles en su Retórica (1454b).

Lo que está en juego aquí es la pertenencia de las armas de Aquiles; se trata de un conflicto de intereses por la propiedad. Esto determina que el uso de la palabra se vea tan fuertemente marcado por las estrategias de la retórica en la búsqueda de la adhesión del auditorio que debe decidir la adjudicación de esa propiedad. ${ }^{5}$ De hecho, el texto comienza con la presentación del auditorium formado por los duces sentados y los soldados -vulgi- de pie, constituidos en una especie de asamblea ad hoc que deberá arbitrar a quién le corresponden las armas del Pelida.

Teniendo en cuenta los postulados de la pragmadialéctica sobre la argumentación, consideramos que en esta discusión ambos contendientes son protagonistas. Si bien Áyax es el iniciador, Ulises responde para sostener su propio punto de vista. ${ }^{6}$ Analizamos a continuación las intervenciones de los oradores, cuya efectividad está sugerida, de alguna manera, por la extensión y por las características del exordio (cfr. Tola, 2010, p. 302).

\subsection{Discurso de Áyax}

El discurso de un Ayax "inpatiens irae (...) torvo vultu" "sin contener su cólera (...) con torvo rostro" (Ov. Met. 13.3-4) abre la discusión, o sea que se presenta como proponente. En los agones de las tragedias griegas, el hecho de ser el primer participante es, en general, un indicio de la resolución del conflicto, ya que suele resultar el perjudicado por la decisión del auditorium/árbitro. Este dato opera como anticipación del desenlace en este texto. Pero si, como dijimos anteriormente, consideramos que en este caso no se trata de llegar a una resolución entre ambas partes, sino que cada contendiente defiende su punto de vista, entendemos que ambos participantes se comportarán como protagonistas y antagonistas alternativamente en la medida que cada uno intenta convencer de la aceptabilidad de su punto de vista.

\footnotetext{
5. Barthes sostiene lo siguiente: "La Retórica (como metalenguaje) nació de procesos a la propiedad. Hacia el año 485 a. C. dos tiranos sicilianos, Gelón y Hierón decretaron deportaciones, traslados de población y expropiaciones para poblar Siracusa y adjudicar lotes a los mercenarios; cuando fueron destituidos por un levantamiento democrático y se quiso volver al ante quo, hubo innumerables procesos pues los derechos de propiedad estaban confusos. Estos procesos eran de un tipo nuevo: movilizaban grandes jurados populares ante los cuales, para convencer, había que ser 'elocuente” (1982, p. 12).

6. "Una discusión crítica se da entre una parte que sostiene un cierto punto de vista (positivo o negativo), el protagonista, y otra parte que desafía este punto de vista, el antagonista. Solo cuando un antagonista se opone al punto de vista del protagonista con un punto de vista inverso es cuando ese antagonista se convierte también en protagonista de un punto de vista" (Van Eemeren, Grootendorst y Snoeck, 2006, p. 37).
} 
Podemos identificar los versos 5 y 6 como el exordium o introducción. Ya las primeras palabras, tanto el verbo como su modificador, "agimus (...) causam" "debatimos este pleito" encuadran claramente el discurso en el genus iudiciale, al igual que la disposición de los compañeros en una asamblea sui generis. Inmediatamente nombra a su oponente, el astuto Ulises, con el cual "confertur" "es comparado". Este comienzo podría ser considerado como un ex abrupto, ya que intempestivamente inicia el pleito sin presentación del conflicto ni captatio benevolentiae: la brevedad del exordio, acompañada por las características de la gestualidad que manifiesta su desmesura, preludia la debilidad del discurso de Áyax:

el primer error de Áyax al tomar la palabra consiste en una falta de control emocional que se plasma en su cuerpo y condena su parlamento al fracaso. Dicha falta de control se vincula, a su vez, con la brevedad misma de su exordium. (Tola, 2010, p. 303)

Ya en la argumentación propiamente dicha, leemos en los primeros versos la dualidad que atravesará no solo el discurso de Áyax, sino el enfrentamiento verbal en su totalidad, dualidad que implica el poder de la acción concreta en la batalla-virtus-frente al poder hacer de las palabras -eloquentia o facundia:

Tutius est igitur fictis contendere verbis, quam pugnare manu, sed nec mihi dicere promptum, nec facere est isti: quantumque ego Marte feroci inque acie valeo, tantum valet iste loquendo.

(Ov. Met.13.9-12)

En efecto, es más seguro competir con palabras inventadas que luchar con las manos. Pero ni yo tengo facilidad para hablar ni ese para actuar, y cuanto valgo yo en la guerra impetuosa $\mathrm{y}$ en la batalla, tanto vale ese disertando.

Así se comienzan a construir dos campos semánticos que resultan opuestos, uno referido al ámbito de la acción -manus, facere, acies- y otro, al del decir-verbum, dicere, loquendo-, ejes argumentativos que recorren todo el discurso y ponen de relieve los dos puntos de vista enfrentados.

En esta instancia se pone de manifiesto la diferencia de opinión que es el origen del desacuerdo: ¿qué es más importante, el arrojo en la lid o la destreza del estratega?

Una vez planteada esta oposición, el enunciador desarrolla su argumentación a partir de enunciados que funcionarán como defensa de su punto de vista, argumentos que se van sumando para desacreditar a su oponente, al tiempo que construyen su propio ethos, ${ }^{7}$ pues entendemos que "toda toma de palabra implica la construcción de una imagen de sí mismo” (Amossy, 1999, p. 1). Aristóteles afirma en Rhet.1356a que el ethos se vincula directamente con aquello "que hace al que habla digno de crédito". En este sentido relevaremos algunas de las estrategias discursivas que contribuyen a esta construcción de una imagen para causar una buena impresión; los rasgos de carácter que el orador

7. La antigua retórica usaba este término para aludir a la construcción de una imagen de sí mismo destinada a garantizar la eficacia del acto oratorio. 
debe mostrar al auditorio. Barthes los llama también "aires" o "tono": "El ethos es en sentido propio una connotación: el orador enuncia una información y al mismo tiempo dice: soy esto, no soy aquello” (1982, p. 63). Podríamos sintetizar diciendo que el ethos es todo lo que en la enunciación discursiva contribuye a construir una imagen del orador destinada al auditorio: tono de voz, elección de las palabras y los argumentos, gestos, posturas, etc.

Consideramos que los argumentos del primer orador/enunciador son en su mayoría ad hominem, porque ponen en tela de juicio los rasgos característicos de su rival, y se basan en una relación sintomática, es decir, a partir de las acciones se infieren las características. Estas son, desde el punto de vista de Áyax, la propensión de Ulises para el engaño, la mentira, la impiedad, la traición a sus compañeros, la cobardía y la debilidad física, ponderando en todos los casos la visión negativa del héroe "como paradigma de crueldad, traición y criminalidad" (Tola, 2010, p. 300). Todos estos aspectos serán probados en el devenir discursivo.

En diferentes enunciados se pone en duda la veracidad de las hazañas atribuidas a Ulises, cuyo único testigo era la noche: "sua narret Ulixes, / quae sine teste gerit, quorum nox conscia sola est!" "que Ulises cuente las suyas, que lleva a cabo sin testigos, de las cuales únicamente es cómplice la noche” (vv. 14-15).

Esta sospecha se funda en situaciones por todos conocidas. Por ejemplo, el ardid del "furore (...) ficto" "con locura fingida” (vv. 36-37) y su intención de no participar en la guerra.

Refuerza estos argumentos hacia el final cuando subraya el hecho de que las proezas de Ulises suceden a escondidas, sin testigos y siempre acompañado por Diomedes, razón por la cual en una especie de "burla" sugiere en caso de que Ulises ganara la contienda, que el premio sea compartido con su compañero Diomedes. Hace hincapié una vez más en la capacidad de engañar, embaucar - decipio-a los incautos:

Quo tamen haec Ithaco, qui clam, qui semper inermis rem gerit et furtis incautum decipit hostem?

(Ov. Met. 23.103-104)

¿Pero para qué dárselas al Ítaco, quien lleva a cabo sus actuaciones a escondidas, siempre sin armas y con sus ardides embauca al desprevenido enemigo?

En los ejemplos hasta aquí citados se sugiere la violación de la máxima de sinceridad, ${ }^{9}$ aspecto que descalifica al oponente.

Luego Áyax apela a su linaje honorable y a su relación de parentesco con Aquiles. Confronta esa noble ascendencia, que lo relaciona con el mismo Pelida, con la de Ulises que lo emparienta con Sísifo,

8. Barthes aclara que "es más adecuado hablar de tonos que de caracteres: tono en el sentido musical y ético que la palabra tenía en la música griega” (1982, p. 63).

9. Van Eemeren menciona cuatro reglas de la comunicación en general: de la claridad, de la sinceridad, de la eficiencia y de la relevancia (2006, p. 59-60). 
personaje mítico que se destaca por sus robos y engaños: "Quid sanguine cretus / Sisyphio furtisque et fraude simillimus illi” “Tú, descendiente de la sangre de Sísifo y muy igual a aquel en robos y engaños" (vv. 31-32). Estamos ahora frente a una argumentación basada en la analogía, puesto que se sugiere una inmediata identificación con Ulises, el "hortator scelerum" "instigador de crímenes" (v. 45). Este argumento será puesto en duda por su validez, en cuanto a su relevancia en términos de adecuación al tema en cuestión, debilidad discursiva que será recuperada por el discurso de su oponente.

Profundiza la descalificación de Ulises al referirse a la relación con sus propios compañeros, cuestionando su fidelidad y empatía, así como su compasión. Relata el despiadado abandono a Filoctetes herido en Lemnos, quien aún vivo profiere maldiciones en contra del Laertíada. También nos cuenta la traición que llevó a la muerte a Palamedes, solo para vengarse por haber develado la mentira de su locura. Finalmente, la desconsideración frente a la ancianidad de Néstor cuando no podía moverse con celeridad. Expresa así su condena moral, apelando a lo censurable de estas acciones desde una mirada de lo éticamente aceptable para la opinión común: "Adspiciunt oculis superi mortalia iustis!" "Los dioses contemplan los asuntos de los mortales con ojos ecuánimes” (v. 70).

Se refiere a continuación a la cobardía de Ulises remitiendo tanto a sus acciones en el campo de batalla como a su condición física. Primero, frente a un ataque de Héctor ante el que debió ser protegido por el escudo del mismo Áyax. Seguidamente, a la defensa de las naves ante el ataque troyano, en la cual también Áyax debe intervenir para salvar la situación.

Alude, para terminar, a la condición física del oponente, acerca de quien afirma que no sería capaz de soportar el peso de las armas por su debilidad y contextura, tanto como por su ineptitud en la batalla. Señala también la necesidad de Ulises de ocultarse siempre para engañar y su propensión a la huida. Así expone las desventajas que implicarían, para un cobarde que huye, el peso de unas armas desproporcionadas a la estatura tanto física como "moral" del rival.

Nos referimos ahora a la construcción del ethos de Áyax como otra estrategia para convencer, para persuadir al árbitro de su superioridad. Exalta su propia figura al mostrarse como opuesto a Ulises; de cada caracterización de su oponente se desprende un argumento a favor para el Telamonio. Por ejemplo, frente a la cobardía de Ulises, destaca su valentía y entrega al salvar a Héctor y en el episodio de las naves.

A diferencia de la locura fingida para no participar de la guerra, y, en todo, caso de haber llegado tarde, recuerda su propia participación temprana y el hecho de haber afrontado todos los peligros y los riesgos desde el comienzo. Resalta la paradoja que implicaría el hecho de entregarle las armas a un soldado que ha retardado todo lo posible su llegada a la guerra.

Añade como último argumento la necesidad de reemplazar su escudo ya que ha sido vapuleado por tantos enfrentamientos audaces, mientras que el de Ulises se mantiene intacto. Así, los escudos funcionan como una sinécdoque de los guerreros.

Consideramos representativo de la imagen de grandeza y valentía que Áyax quiere mostrar a sus compañeros y jefes, el siguiente enunciado: "Aiax armis, non Aiaci arma petuntur" "Ayax es reclamado por las armas, no las armas por Áyax” (v. 97). Así mediante la personificación encumbra su 
figura al postular que las mismas armas, sinécdoque de Aquiles, reclaman el honor de ser obtenidas por el Telamonio.

Otros de los recursos que aparecen son las preguntas retóricas y los vocativos para dirigirse a sus interlocutores, tanto para apelar a soldados y jefes, el auditorium/árbitro, como al oponente, Ulises. Lo hace en ocasiones a través del mismo nombre, otras con algún epíteto y otras, simplemente, con el verbo en segunda persona.

Termina apelando a la función social de la asamblea. En el final de su discurso -epilogus- se dirige directamente al árbitro pidiendo una intervención para definir su decisión, es al igual que el exordium muy breve, un ex abrupto: "Denique (quid verbis opus est?) spectemur agendo!" "Finalmente (¿qué necesidad hay de palabras?) que se nos vea actuar” (v. 120), caracterizado por su fuerte poder de síntesis al insistir en la oposición que origina el desacuerdo opus versus verbum, y reafirmar su punto de vista.

La intervención de un narrador en tercera persona da pie al próximo discurso del oponente, Ulises. Describe su actitud física, marcando su fuerte presencia, que funciona como una primera estrategia de persuasión; en términos de Tola "la actio entendida como cierta elocuencia del cuerpo (...) Ulises manifiesta una perfecta adecuación de su cuerpo a su propósito” (2010, p. 303-304). E1 narrador agrega además que "neque abest facundis gratia dictis" "ni faltó la gracia a sus elocuentes palabras" (v. 127) con las que refutará uno a uno los argumentos de Áyax:

Laertius heros

adstitit atque oculos paulum tellure moratos

sustulit ad proceres exspectatoque resolvit

ora sono, neque abest facundis gratia dictis.

(Ov. Met. 13.124-127)

el héroe hijo de laertes se puso en pie y levantó los ojos, que había detenido un poco en el suelo, hacia los próceres y abrió la boca con el sonido esperado, y no faltó gracia a sus elocuentes palabras.

\subsection{Discurso de Ulises}

Para analizar el discurso de Ulises, que supera ampliamente en extensión al de Áyax, rescatamos la primera de las tres categorías o especies de las que habla Aristóteles en Retórica 1356a: el ethos. Ulises utiliza insistentemente a lo largo de su alocución, desde el exordium (vv. 128-139) y sobre todo en la refutatio (vv. 268-338), las posibilidades que le brinda la prueba de su ethos y lo hace inicialmente mediante la captatio benevolentiae (ausente en el discurso de Áyax) al plantear que siente el mismo dolor que los soldados y los jefes guerreros por la muerte de Aquiles. Y no solo esto: sus palabras se ven reforzadas por el gesto, explicitado por el narrador -típicamente ovidiano-, mediante una expresión parentética: ${ }^{10}$ "manuque simul veluti lacrimantia tersit / lumina” "y a la vez con la mano restregó sus ojos como si estuviera derramando lágrimas” (vv. 132-133).

10. En la "Introducción" a su edición de Metamorfosis, Álvarez e Iglesias (2011, p. 99, n. 377) acotan que Van Albrecht (1964) estudió la función literaria de los paréntesis en Ovidio y concluyó que mediante ellos el poeta se hace presente en la narración y guía la atención de sus lectores para hacerlos sus cómplices. 
Asimismo retoma en la probatio (vv.140-267), notablemente más extensa que la de su oponente, algunos de los argumentos esgrimidos por este, y lo hace ya sea para ironizar sobre ellos, desbaratar su andamiaje retórico o solventar la construcción de su propio ethos. De este modo, en un primer momento, intenta desacreditar la prueba del linaje explicitada por Áyax, exponiendo tres razones lógicas: a) su propia familia también desciende de Júpiter y por doble vía: paterna y materna; b) en su estirpe no hay condenados ni exiliados como en la de Áyax (su padre Telamón y su tío Peleo fueron homicidas y expulsados de su tierra); c) antes que el antecedente del linaje como elemento de juicio para heredar las armas se debería recurrir a la prueba del valor. Es por esto que de aquí en más su argumentación se orientará en el sentido de fortalecer su imagen como la de un guerrero cuyo desempeño en el ejercicio de la palabra vuelve imprescindible su intervención para obtener la victoria sobre los troyanos, y cuya labor de astucia discursiva se puso en juego incluso antes de la partida de la flota griega desde Áulide, cuando los jefes estaban siendo convocados por Menelao para la hazaña épica.

Uno de los recursos retóricos empleados en abundancia para fortalecer la construcción de esa imagen positiva es la hipérbole. En este sentido consideramos que el emisor viola deliberadamente la regla de la sinceridad con el objeto de engrandecer su propia imagen. ${ }^{11}$ Ulises se adjudica todas las hazañas realizadas por Aquiles, por el hecho de haber sido él mismo quien con su astucia había desbaratado la estrategia del disfraz femenino que Tetis había tramado para que su hijo no fuera a la guerra, ardid con el que todos, incluso Áyax, habían sido engañados: "Ergo opera illlius mea sunt” "Así pues las obras de aquel son mías” (v. 171). En los versos 304 y 305, en referencia al mismo episodio, dice de sí mismo: "deprensus Ulixis / ingenio tamen ille" "fue descubierto por el talento de Ulises".

Con un razonamiento igualmente hiperbólico se adjudica también las hazañas de Áyax, dado que este guerrero, en ocasión del engaño al que habían sido sometidos todos los soldados por el sueño enviado por Zeus a Agamenón, se había visto obligado a suspender su huida debido a la astucia de Ulises. ${ }^{12}$ Dice al respecto:

Erigor et trepidos cives exhortor in hostem amissamque mea virtutem voce reposco.

Tempore ab hoc, quodcumque potest fecisse videri fortiter iste, meum est, qui dantem terga retraxi.

(Ov. Met. 13.234-237)

Me levanto e incito a los temerosos ciudadanos contra el enemigo y con mi palabra les exijo el valor perdido. A partir de ese momento cualquier cosa que pueda parecer que ha hecho este con valentía, me pertenece a mí, que obligué a volver al que daba la espalda.

Con similar insistencia, más adelante en la probatio, expone los méritos de su habilidad discursiva mediante la referencia a su ya lejana intervención para convencer a Agamenón de sacrificar a Ifigenia (requisito impuesto por Ártemis para favorecer con buenos vientos la partida de la flota

11. Van Eemeren et al. sostienen que un hablante saca ventaja cuando viola deliberadamente alguna de las reglas de la comunicación: "Violando o pareciendo que se viola una o más de las reglas, al mismo tiempo que no se vulnera enteramente el principio de la comunicación, se hace claro para el oyente que se quiere significar algo diferente o algo más que lo que se dice" (2006, p. 60).

12. El episodio se relata en Ilíada II.1-141. 
griega): "ego mite parentis / ingenium verbis ad publica commoda verti” “yo cambié con mis palabras el suave carácter del padre para el bien común" (vv. 187-188), como así también su astuto empleo de la palabra para que Clitemnestra accediera a llevar a su hija hasta la costa de Áulide: "Mittor et ad matrem, quae non hortanda, sed astu / decipienda fuit" "Soy enviado también ante la madre, que no podría ser convencida, sino engañada con astucia” (vv. 193-194). Aprovecha la ocasión para aludir a la incompetencia de Áyax en este sentido, y lo hace también con una hipérbole: "quo si Telamonius isset, / orba suis essent etiam nunc lintea ventis" "si hubiese ido allí el Telamonio, todavía estarían las velas privadas de sus vientos" (vv. 194-195).

Pero Ulises no se limita a las palabras en su trabajo sobre el propio ethos: también recurre a un gesto que constituye un fuerte golpe de efecto destinado a exacerbar el pathos del auditorio. Baja su túnica con la mano y muestra las heridas: "Sunt et mihi vulnera, cives, / ipso pulchra loco; nec vanis credite verbis, / adspicite en!" "También yo tengo heridas, ciudadanos, hermosas por su misma localización, y no confiéis en vanas palabras. ¡Ea, miradlas!” (vv. 262-264).

En la refutatio el énfasis está puesto en la tarea de debilitar el punto de vista de su contrincante. Frente al argumento ad hominem de Áyax, quien había sostenido que Ulises no sería será capaz de soportar el peso de las armas, el Laertíada no solo relata que llevó sobre sus hombros el cuerpo de Aquiles muerto y sus armas, sino que redobla la apuesta aduciendo la ignorancia del Telamonio, incapaz de entender las imágenes grabadas en el escudo: “...neque enim clipei caelamina novit”. "Pues él no distingue los cincelados del escudo" (v. 291). Recordemos que Áyax solo había mencionado "clipeus vasti caelatus imagine mundi" "el escudo cincelado con la imagen del enorme mundo" (v. 110). Ulises en cambio, detalla en una breve ékphrasis los elementos que aparecen allí:

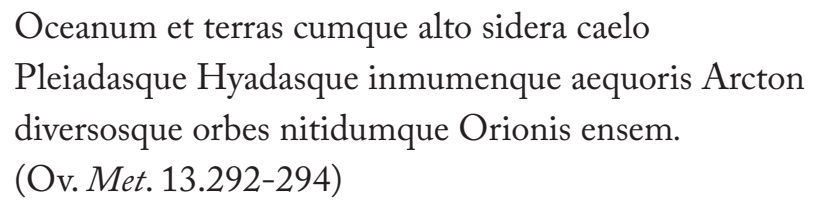

Océano, las tierras y las constelaciones, junto con el elevado cielo, las Pléyades, las Híades y la Osa libre del mar, las diferentes ciudades y la brillante espada de Orión.

No deja de recurrir el Laertíada también al insulto descarnado, en referencia directa a la inferioridad mental de su adversario: "rudis et sine pectore miles" "soldado rudo y sin corazón" (v. 290). Finaliza su argumento ad hominem con un ataque directo contra la inteligencia de Áyax: reclama unas armas en las cuales se encuentra grabado un "texto" que no es capaz de comprender: "postulat, ut capiat, quae non intellegit, arma" "reclama hacerse con unas armas que no comprende" (vv. 295-296). Del mismo modo emplea contra él expresiones como "stolidae linguae" "estúpida lengua" (v. 306) o "Aiacis stolidi” “estúpido Áyax” (v. 327).

Como estrategia para desacreditar a su oponente, Ulises recurre además al empleo de preguntas retóricas, que apuntan básicamente a señalar por un lado la debilidad de Áyax en lo que respecta a lo discursivo, es decir, en el empleo de la palabra activa, la palabra como instrumento de poder para 
convencer al otro: "Quid facis interea, qui nil nisi proelia nosti? / quis tuus usus erat?" ¿Qué haces entre tanto tú, que no conoces nada a no ser los combates? ¿Cuál era el uso que podía hacerse de ti?" (vv. 210-211) y por el otro a la supuestamente escasa estima de sus compañeros: "Denique de Danais quis te laudatve petitve?” ¿Quién de los dánaos te alaba o te busca?” (v. 238). El recurso de las preguntas se extiende hasta el epílogo: "fortis ubi est Aiax? Ubi sunt ingentia magni / verba viri? Cur hic metuis?” “Dónde está el valiente Áyax? ¿Dónde están las enormes palabras de un gran héroe? ¿Por qué aquí tienes miedo?” (vv. 340-341).

Mediante la denominada "falacia patética"13 minimiza en la refutatio lo afirmado por Áyax en versos 7 y 8 sobre su accionar en el episodio del incendio que amenazó a las naves griegas. ${ }^{14}$ Ulises intenta ganarse la simpatía de los soldados resaltando la labor colectiva en ese salvataje y no dejando de evocar el recuerdo de la eficiente participación de Patroclo en aquella ocasión: "sed ne communia solus / occupet atque aliquem vobis quoque reddat honorem" "Pero para que él solo no se adueñe de lo que es común a todos y os devuelva a vosotros también algún honor” (vv. 271-272). En este sentido debemos señalar la importancia que para la Pragmadialéctica tiene el auditorio en la construcción y diseño de las estrategias retóricas por parte de quien emite el discurso (Londoño y Herrera, 2012, p. 277).

Es de notar que Ulises emplea en la refutatio e incluso en el epílogo, argumentos que deberían formar parte de la probatio; no deja de ensalzar las hazañas propias al tiempo que refuta los puntos de vista de su oponente. Da por sentado mediante una sentencia de apariencia gnómica la superioridad de la mente sobre el cuerpo: "Qui nisi pugnacem sciret sapiente minorem" "si no supiera que el que lucha es más pequeño que el sabio” (v. 354), superioridad que a lo largo de su alocución no ha cesado de atribuirse.

La última acción valerosa de la que Ulises se jacta en su argumentación es la apropiación de la estatua de Minerva que se encontraba en poder de los troyanos, referencia que le será de gran utilidad para el cierre patético de su discurso, cuando señalando la estatua concluye diciendo que, si no le dan a él las armas, deben dárselas a la diosa: "aut si mihi non datis arma / huic date -et ostendit signum fatale Minervae" "y si no me dais a mí las armas, dádselas a ella -y mostró la estatua de Minerva signada por el destino" (vv. 380-381).

El narrador se ocupa de registrar la reacción del auditorio; una vez más se resalta la fuerza poderosa del ejercicio de la palabra -facundia-, que actúa sobre las personas e imprime decisiones: "Mota manus procerum est, et quid facundia posset, / re patuit, fortisque viri tulit arma disertus" "Se conmovió el grupo de próceres y quedó en evidencia qué poder tenía la elocuencia, y el que había disertado obtuvo las armas del valeroso héroe" (vv. 382-383).

Cierra la disputa una última intervención de Áyax, víctima de sus pasiones. No pudiendo aceptar su derrota decide su muerte por mano propia para demostrar que "ne quisquam Aiacem possit superare nisi Aiax" "para que nadie pueda vencer a Áyax a no ser Áyax” (v. 390). Así el varón invicto es vencido por su propio furor: "invictumque virum vicit dolor" "el dolor venció a un hombre invicto" (v. 386).

13. "Se llama falacia patética el jugar con las emociones de la audiencia" (Van Eemeren et al., 2006, p. 129).

14. Iliada XV.674-746. 


\section{Conclusión}

En el desarrollo de nuestro análisis hemos observado que en la construcción del discurso argumentativo adquiere relevancia la elección de diferentes estrategias que se ponen en juego por parte de cada uno de los protagonistas para sostener con eficacia sus puntos de vista. De esta manera, en el juicio por las armas de Aquiles, ambos contendientes intentarán lograr su propósito: la adhesión del auditorio a una proposición. Los argumentos deberán no solo crear una disposición a la acción sino también su ejecución de manera inmediata. Es en este sentido que el sujeto enunciador se convierte en un verdadero estratega y el lenguaje la arena propicia para la lucha, como dijimos anteriormente.

Áyax construye el perfil de su oponente desde una perspectiva negativa, ya que sus argumentos, en su mayoría ad hominem, buscan la descalificación personal del rey de Ítaca, a la vez que fortalecen por oposición su propio ethos. Además no solo pone en duda muchas de las hazañas atribuidas a Ulises, sino que manifiesta la imposibilidad de probarlas y cuestiona sus "valores" en relación con la fides para con sus compañeros. Asimismo, recurre a preguntas retóricas y vocativos para dirigirse a sus interlocutores e involucrarlos explícitamente; no obstante, su discurso carece del poder de persuasión que manifiesta el de su adversario, por lo tanto no es eficaz.

Ulises responde a los ataques de su oponente refutando cada una de sus proposiciones. Apela sin reparos a la hipérbole para enaltecer su propia figura, a la vez que subestima constantemente al adversario especialmente en lo relacionado con su inteligencia. Su triunfo es un ejemplo más del poder del lenguaje. Sus palabras devienen armas, se esgrimen y le permiten llevar a cabo su objetivo: no solo la obtención del premio anhelado, sino también el reconocimiento como el más grande de los guerreros. Ulises despliega las habilidades discursivas que han abastecido su fama desde la Odisea; acordamos con Tola (2010, p. 317) en que "la reelaboración ovidiana del célebre episodio mítico se centra en la explicitación de los rasgos proverbiales de Ulises mediante la puesta en escena de su discurso”.

En esta disputa por el derecho a la herencia de las armas, otro debate parece entrar en juego: la cuestión del peso relativo de la virtus épica tradicional frente a la facundia, como fuerzas contrapuestas que definen la superioridad (viril, por supuesto, en este contexto). La victoria de Ulises parece mostrar con claridad cómo se dirime esta elección en términos ovidianos: "et quid facundia posset, / re patuit" (vv. 382-383).

\section{Referencias bibliográficas}

Amossy, R. (1999). La noción de ethos de la retórica al análisis del discurso (J. Dothas, trad.). https://bit.ly/3wQyrNH.

Arán, P. (dir. y coord.) (2006). Nuevo Diccionario de la Teoría de Mijaíl Bajtín. Córdoba, Ferreyra.

Aristóteles (2014). Retórica. Madrid, Alianza.

Bajtín, M. (2011). Estética de la creación verbal (T. Bubnova, trad.). Buenos Aires, Siglo XXI.

Barei, S.y Rinaldi, N. (1996). Cuestiones retóricas. Estética y argumentación. Córdoba, Red de Editoriales de Universidades Nacionales. 
Barthes, R. (1982). La antigua retórica. Ayuda memoria. Barcelona, Ediciones Buenos Aires.

Barthes, R. (1993). La aventura semiológica. Buenos Aires, Paidós.

Carretero, F. (comp.) (2015). Pragmadialéctica y argumentación. Estudios en honor a Franz van Eemeren. Guadalajara, Editorial Universitaria.

Londoño, D. y Herrera, J. (2012). Coincidencias entre la Argumentación Pragmadialéctica y la Novíssima Retórica. Revista Latinoamericana de Ciencias Sociales, Niñez y Juventud, 10 (1), 271-285.

Maingueneau, D. (2002). Problèmes d'ethos. Pratiques, 113/114, 55-67.

Ovidio (1983). Metamorfosis. Barcelona, Bruguera.

Ovidio (2011). Metamorfosis. Madrid, Cátedra.

Ruiz de Elvira, A. (1975). Mitología clásica. Madrid, Gredos.

Tola, E. (2010). ... Quid facundia posset / Re patuit (Ov., Met. XIII 382-383): las estrategias oratorias de Ulises en el armorum iudicium ovidiano. Emerita, LXXVIII (2), 299-318.

Van Eemeren, F.; Grootendors, R. y Snoeck, F. (2006). Argumentación: análisis, evaluación, presentación (R. Marafioti, trad.). Buenos Aires, Biblos.

*Marcela Inés Coll es Profesora en Enseñanza Media y Superior en Letras en la Universidad Nacional de San Juan. Es Profesora Asociada de Lengua y Literatura Latina I y II del Departamento de Letras de la Facultad de Filosofía, Humanidades y Artes de la UNSJ. Es especialista en Filología Clásica por la UN de Cuyo. Ha integrado y codirigido proyectos de investigación en el Instituto de Literaturas Ricardo Güiraldes de la UNSJ. Sus trabajos se refieren a la reescritura de mitos clásicos en textos literarios contemporáneos en el marco de la Literatura Comparada.

** María Celina Perriot es Profesora de Enseñanza Media y Superior en Letras y Magister en Letras por la Universidad Nacional de San Juan. Docente de Lenguas y Literaturas Clásicas en el Departamento de Letras de la Facultad de Filosofía, Humanidades y Artes de la UNSJ. Directora de proyectos de investigación en el Instituto de Literaturas Ricardo Güiraldes de la UNSJ.

RECIBIDO: 09/04/2021

ACEPTADO: 07/06/2021 